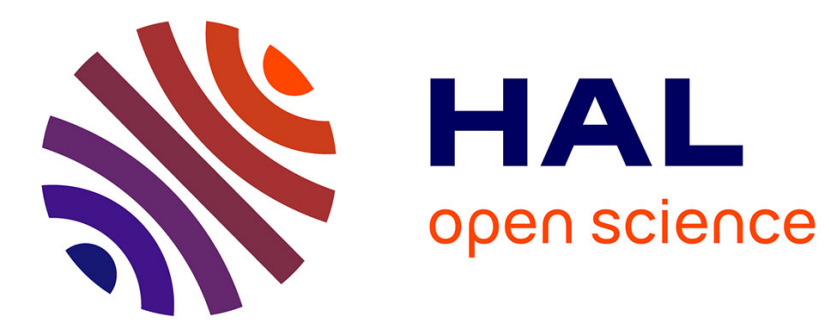

\title{
Monte Carlo Simulation for Chipless RFID Orientation Sensor
}

\author{
Olivier Rance, Nicolas Barbot, Etienne Perret
}

\section{To cite this version:}

Olivier Rance, Nicolas Barbot, Etienne Perret. Monte Carlo Simulation for Chipless RFID Orientation Sensor. 2020 IEEE International Symposium on Antennas and Propagation and North American Radio Science Meeting, Jul 2020, Montreal, France. pp.1199-1200, 10.1109/IEEECONF35879.2020.9329985 . hal-03235834

\section{HAL Id: hal-03235834 \\ https://hal.science/hal-03235834}

Submitted on 26 May 2021

HAL is a multi-disciplinary open access archive for the deposit and dissemination of scientific research documents, whether they are published or not. The documents may come from teaching and research institutions in France or abroad, or from public or private research centers.
L'archive ouverte pluridisciplinaire HAL, est destinée au dépôt et à la diffusion de documents scientifiques de niveau recherche, publiés ou non, émanant des établissements d'enseignement et de recherche français ou étrangers, des laboratoires publics ou privés. 


\title{
Monte Carlo Simulation for Chipless RFID Orientation Sensor
}

\author{
Olivier Rance*, Nicolas Barbot, Etienne Perret \\ LCIS \\ Univeristé Grenoble Alpes, Grenoble INP \\ Valence, France \\ olivier.rance@1cis.grenoble-inp.fr, nicolas.barbot@lcis.grenoble-inp.fr, etienne.perret@lcis.grenoble-inp.fr
}

\begin{abstract}
This article presents an application of the Monte Carlo method for the evaluation of a chipless RFID orientation sensor in presence of noise. The working principle of the sensor is presented and an analytical model is derived. The sensitivity of the sensor to distance is put in evidence both with uncertainty propagation of the first order approximation of the model and by Monte Carlo Simulation. The Monte Carlo approach is applied successfully even for the nonlinear parts of the model contrary to the first order approach.
\end{abstract}

Keywords-Chipless RFID; orientation sensor; error analysis, Monte Carlo

\section{INTRODUCTION}

Chipless RFID has been first introduced as an identification technology offering the same advantages as the classical RFID in terms of reading versatility but with a label at a cost comparable to barcode. However the lake of a chip introduces important limitations in the data capacity or read range achievable by a chipless RFID system. In order to remain competitive, chipless RFID needs to propose new functionalities like sensing which are impossible to realize with the barcode technology. Sensors based on chipless RFID technology have generally the advantage of being contactless, low cost and battery less solutions which can eventually be deployed in harsh environment. Although central for sensor characterization, only few studies are carried out about the effect of noise or measurement errors when designing a chipless RFID sensor. In this article we show how the Monte Carlo (MC) method can be beneficial to evaluate performances of a chipless RFID orientation sensor in real environment (i.e. in presence of noise).

\section{ChIPless RFID ORIENTATION SENSOR}

The chipless RFID orientation sensor used in this study has been described and justified analytically in [1]. The label is composed of a resonator (gap coupled dipoles in Fig. 1) which is attached to an object in order to determine its orientation. The sensor uses the polarization mismatch between the tag and the antennas for orientation determination. A wave with vertical (respectively horizontal) polarization is send to the tag. The resonator is sensitive to electromagnetic waves having linear polarization oriented along the strip direction $(\theta$ in Fig. 1) such that the backscattered E-field is linearly polarized along $\theta$ with an amplitude proportional to $\cos \theta$ (respectively

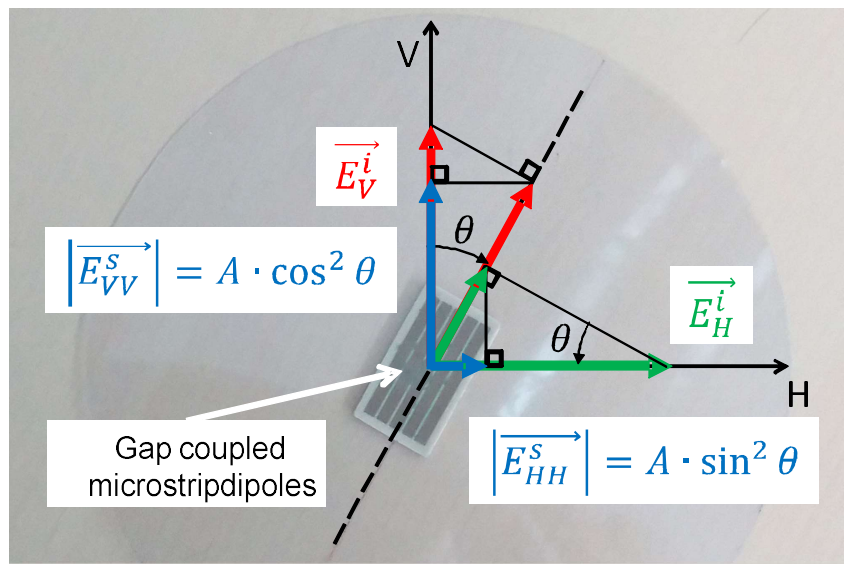

Fig. 1. Orientation sensor principle. The estimation of the orientation angle $\theta$ exploites the polarization mismatch between the dipoles and the antennas.

$\sin \theta$ ). A second orthogonal projection takes place at the receiving antennas such that the co-polarization elements of the scattering matrix are given by [1]:

$$
\begin{aligned}
& \left|S_{H H}(\theta)\right|=A \cdot \sin ^{2} \theta, \\
& \left|S_{V V}(\theta)\right|=A \cdot \cos ^{2} \theta .
\end{aligned}
$$

Note that in (1), (2) A is a scalar which depends on the distance between the tag and the antennas due to path attenuation. A simple way to eliminate $\mathrm{A}$ is to consider the ratio of $S_{H H}$ over $S_{V V}$, leading to:

$$
\hat{\theta}=\arctan \left(\sqrt{\frac{\left|S_{H H}\right|}{\left|S_{V V}\right|}}\right) .
$$

Although (3) suggests that the system is independent to distance, it is clear that in presence of noise the signal-to-noise ratio (SNR) will certainly limit the sensor performances for large reading distances.

\section{ERROR ANALYSIS}

\section{A. First order Taylor series approximation}

A common way to evaluate measurement uncertainty is to consider a first order Taylor series approximation (FOTSA) of the model and to use classical laws for uncertainty propagation 
[2]. We consider that the noise introduce uncertainties on both $\left|\mathrm{S}_{\mathrm{VV}}\right|$ and $\left|\mathrm{S}_{\mathrm{HH}}\right|$ which are assumed to be independent. The propagation of uncertainty is then classically given by:

$$
\delta \hat{\theta}=\sqrt{\left(\frac{\partial \hat{\theta}}{\partial\left|S_{V V}\right|} \delta\left|S_{V V}\right|\right)^{2}+\left(\frac{\partial \hat{\theta}}{\partial\left|S_{H H}\right|} \delta\left|S_{H H}\right|\right)^{2}},
$$

which gives, after calculation of the partial derivatives:

$$
\Delta \hat{\theta}=\sqrt{\left(\frac{\tan \theta}{2} \cdot \frac{\Delta\left|S_{V V}\right|}{A}\right)^{2}+\left(\frac{1}{2 \tan \theta} \cdot \frac{\Delta\left|S_{H H}\right|}{A}\right)^{2}},
$$

Where $\Delta\left|S_{V V}\right| / A$ and $\Delta\left|S_{H H}\right| / A$ correspond to normalized errors which in presence of constant noise are increasing with distance due to lower values of A (path loss). From (5) it is also clear that the uncertainty of the estimation depends on the angle $\theta$ being measured. The standard deviation $\Delta \hat{\theta}$ calculated from (5) for a SNR of $20 \mathrm{~dB}$ is represented with respect to $\theta$ on Fig 2. Although informative this approach is valid only when (3) is approximately linear, leading to an overestimation of the noise impact for $\left[0^{\circ}, 20^{\circ}\right],\left[70^{\circ}, 90^{\circ}\right]$. The range of validity of

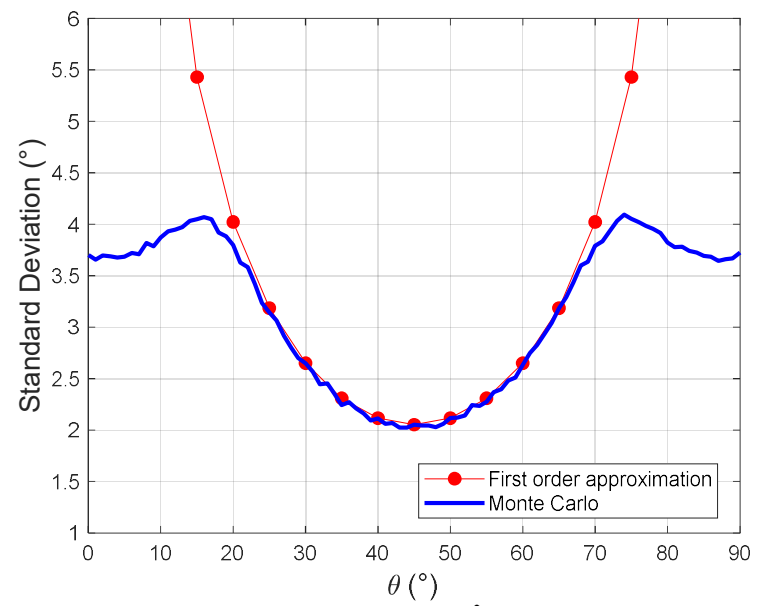

Fig. 2. Standard deviation of the estimated $\hat{\theta}$ in presence of gaussian noise (SNR of $20 \mathrm{~dB}$ ) with respect to $\theta$. Comparison between of the First order approximation and the Monte Carlo approaches.

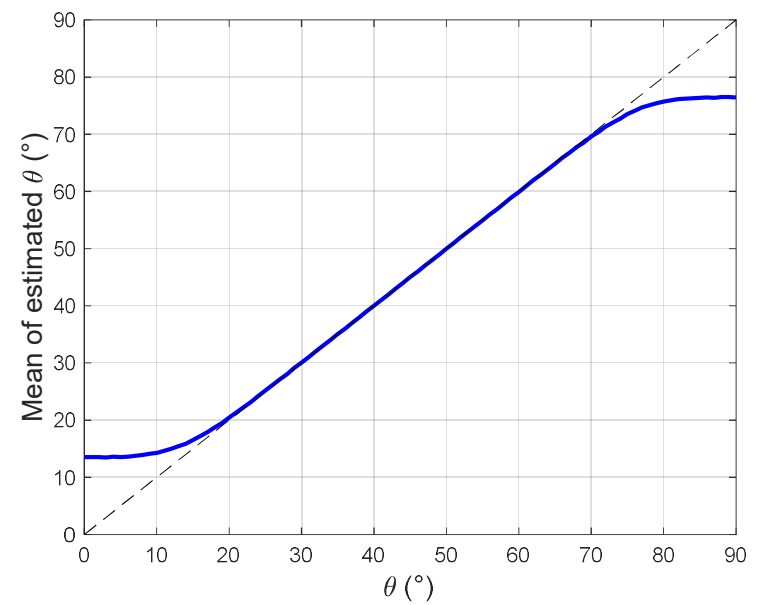

Fig. 3. Mean Value of the estimated $\hat{\theta}$ from Monte Carlo Simulation with additive gaussian noise. The estimator is biased around $0^{\circ}$ and $90^{\circ}$. the theoretical results can be improved by taking higher order model.

\section{B. Monte Carlo Simulation}

Although being computationally intensive, the MC approach [3] has a number of advantages compared to the previous approach. First MC works with the full measurement model rather than a linear approximation of it. MC also avoids the calculation of the partial derivatives which can become difficult when more complicated model is used. And finally MC propagates distributions instead of uncertainties.

The MC has been applied to the model in order to provide a more realistic estimate of the noise impact near $0^{\circ}$ and $90^{\circ}$. For this, a white Gaussian noise with a standard deviation corresponding to a SNR of $20 \mathrm{~dB}$ has been added to both real and imaginary parts of $\mathrm{S}_{\mathrm{VV}}$ and $\mathrm{S}_{\mathrm{HH}}$ (sample size of 10,000 points for each value of $\theta$ ). The model (3) has been applied to each point of the input sample and the uncertainty information have been extracted from the output sample using matlab dedicated functions.

When measurements are corrupted by noise, this noise impacts the estimators by two different ways: a bias, which is a systematic error between the estimated value and the true orientation of the tag (characterized by the mean of the estimator); and a random error, which can be characterized by its standard deviation.

The variation of the standard deviation as a function of $\theta$ is represented in Fig. 2. A good agreement is observed in the interval $\left[20^{\circ}, 70^{\circ}\right]$ between MC and FOTSA. The MC method provides more realistic results in the $\left[0^{\circ}, 20^{\circ}\right],\left[70^{\circ}, 90^{\circ}\right]$. The mean value of the estimate $\hat{\theta}$ obtained from $\mathrm{MC}$ method is represented as a function of $\theta$ in Fig. 3. We can see that the noise introduces a bias in the vicinity of $0^{\circ}$ and $90^{\circ}$.

\section{CONCLUSION}

The first order Taylor series approximation method and the Monte Carlo method have been compared in order to evaluate the impact of noise for a chipless RFID orientation sensor. The two methods are showing good agreement when the model is nearly linear. The MC approach has been applied successfully where the FOTSA failed to produce realistic estimate due to the highly nonlinear behavior of the model.

\section{ACKNOWLEDGMENT (}

This work is funded by the European Research Council (ERC) under the European Union's Horizon 2020 research and innovation program (Grant $\left.\mathrm{N}^{\circ} 772539\right)$

\section{REFERENCES}

[1] N. Barbot, O. Rance and E. Perret, "Angle Sensor Based on Chipless RFID Tag," in IEEE Antennas and Wireless Propagation Letters. (early access).

[2] "Guide to the Expression of Uncertainty in Measurements", $1^{\text {st }}$ edition, International Organization for Standardization, Geneva, Switzerland, 1993.

[3] N. M. Ridler and M. J. Salter, "A generalised approach to the propagation of uncertainty in complex S-parameter measurements," 64th ARFTG Microwave Measurements Conference, Fall 2004., Orlando, FL, USA, 2004, pp. 1-14. 